\title{
Young WI-38 human fibroblasts apoptosis after to staurosporine exposure: a preliminary assessment
}

\author{
F. Leal-Seabra* L. Matos******* H. Almeida*****
}

* Laboratório de Biologia Celular e Molecular, Faculdade de Medicina da Universidade do Porto, Alameda Hernâni Monteiro, 4200-319 Porto, Portugal

** Faculdade de Ciências da Nutrição e Alimentação da Universidade do Porto, Rua Dr. Roberto Frias, 4200-645 Porto, Portugal

*** Instituto de Biologia Molecular e Celular - IBMC, Rua do Campo Alegre, 823, 4150-180 Porto, Portugal

fatima.seab@gmail.com

Human fibroblasts cell culture is an important technique for the study of cell biology under various conditions, as exposure to apoptotic stimuli such as UV radiation or hydrogen peroxide administration or chemotherapeutic agent derivatives from staurosporine (STP) [1]. STP, isolated from Streptomyces staurospores, is a general inhibitor of protein kinases, and is commonly used to induce apoptosis in a variety of cell in cultures as tumor cell lines, lymphocytes, neurons and osteoblasts [2,3]. The mechanism by which STP induce cell death is still unkown. Some studies refer that STP induced cell death courses with cytochrome $c$ release, caspase-dependent pathway activation, especially caspase-3, and is inhibited by $\mathrm{Bcl}-2$ overexpression [2]. However cell death still occurs after caspase inhibition by z-VAD-fmk suggesting that caspase independent pathway is also activated [4].

In the setting of programmed cell death studies with fibroblasts, it is important to verify dose dependent features upon submission of cells to a predictable apoptotic stimulus like STP. The aim of this work was to quantify STP-induced apoptosis of young WI-38 human fibroblasts derived from normal embryonic lung [5].

The cells were cultured in BME with $10 \%$ FBS in T75 culture flasks (Orange Scientific $®$ ) and maintained at $37^{\circ} \mathrm{C}, 5 \% \mathrm{CO}_{2}$. Cells were continuously passaged for up to 27 cumulative population doublings (CPD) and subcultivated to 24 -well plates (Orange Scientific $\left(\right.$ ) at a density of $2 \times 10^{4}$ cells/well. Experimental groups consisted on $1 \mu \mathrm{M}$ and 10 $\mu \mathrm{M}$ STP in DMSO (Sigma-Aldrich®), control (BME added) and vehicle control (DMSO) for 8 or 24 hours. Cells were fixed with methanol/acetic acid. The nuclei were stained with DNA fluorochrome H33258 (Sigma-Aldrich®) and observed in Carl Zeiss ApoTome (Zeiss AX10). The apoptotic index was determined by counting a total of 200 nuclei [6].

During the culture, the confluence of cells in wells was less conspicuous after STP exposure when compared to controls.

Apoptotic features, as membrane blebbing, cell shrinkage, chromatin condensation and nuclear fragmentation, were enhanced in cells exposed to STP (Fig.1). The apoptotic index (\%) for $8 \mathrm{~h}$ and 24h exposure to STP $1 \mu \mathrm{M}$ and 10 $\mu \mathrm{M}$, BME and DMSO was 75 / 93; 58 / 96; 5 / 1 and 6 / 0,2, respectively (Fig.2).

STP administration resulted in remarkable induction of apoptotic features in a large number of fibroblasts in culture. The effect is time dependent. In fact, at $24 \mathrm{~h}$ almost all cells entered in apoptosis, whatever the dose of STP used. The results do not indicate however that the effect is dose dependent, a point that needs additional studies. 


\section{References}

[1] National Cancer Institute - U.S. National Institutes of Health, Midostaurin, available on http://www.cancer.gov/Templates/drugdictionary.aspx?CdrID=462346, access in $28^{\text {th }}$ February 2009 [2] M. Deshmukh, E.M. Johnson Jr, Cell Death Differ, 7 (2000) 250.

[3] H.J. Chae, J.S. Kang, J.O. Byun, K. S. Han, D.U. Kim, S.M. Oh, H.M. Kim, S.W. Chae, H.R. Kim, Pharmacol Res, 42(2) (2000) 373.

[4] C.A. Belmokhtar, J. Hillion, E. Ségal-Bendirdjian, Oncogene, 20 (2000) 3354.

[5] L.Hayflick, P.S. Moorhead, Exp Cell Res, 25 (1961) 585.

[6] G. Argentin, R. Cicchetti, Toxicol Sci, 79 (2004) 75.
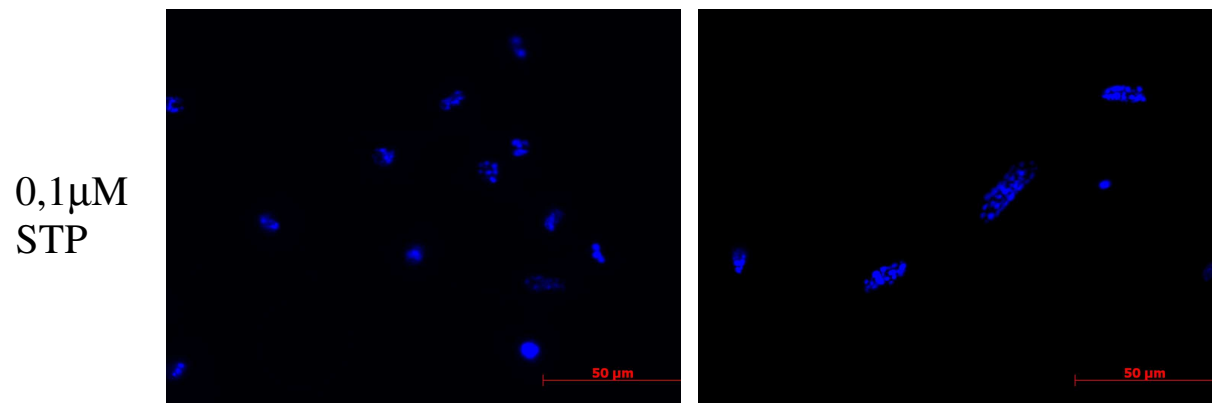

$1 \mu \mathrm{M}$

STP

BME
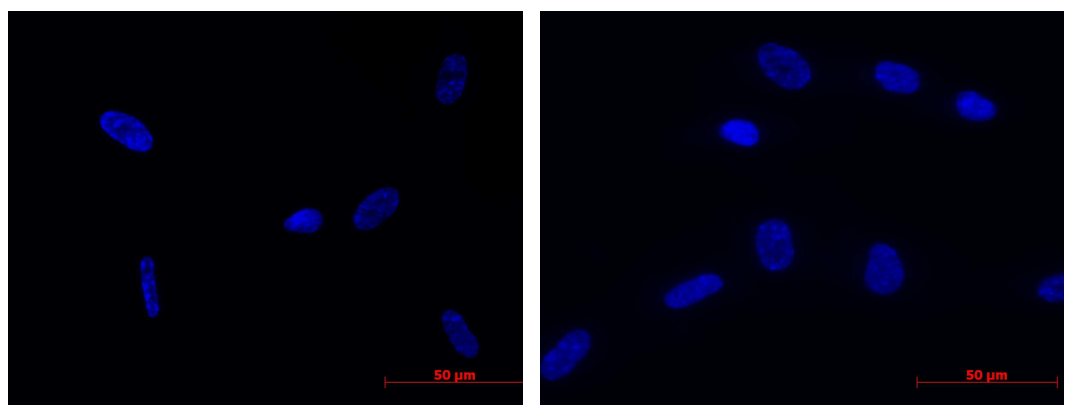

DMSO

Fig. 1. Morphological analysis of apoptosis induced by STP in WI-38 human fibroblast. Typical nuclear features of apoptosis were evidenced by Hoechst 33258. Cultures were incubated with $0,1 \mu \mathrm{M}$ STP, $1 \mu \mathrm{M}$ STP, BME and DMSO, respectively for $8 \mathrm{~h}$.

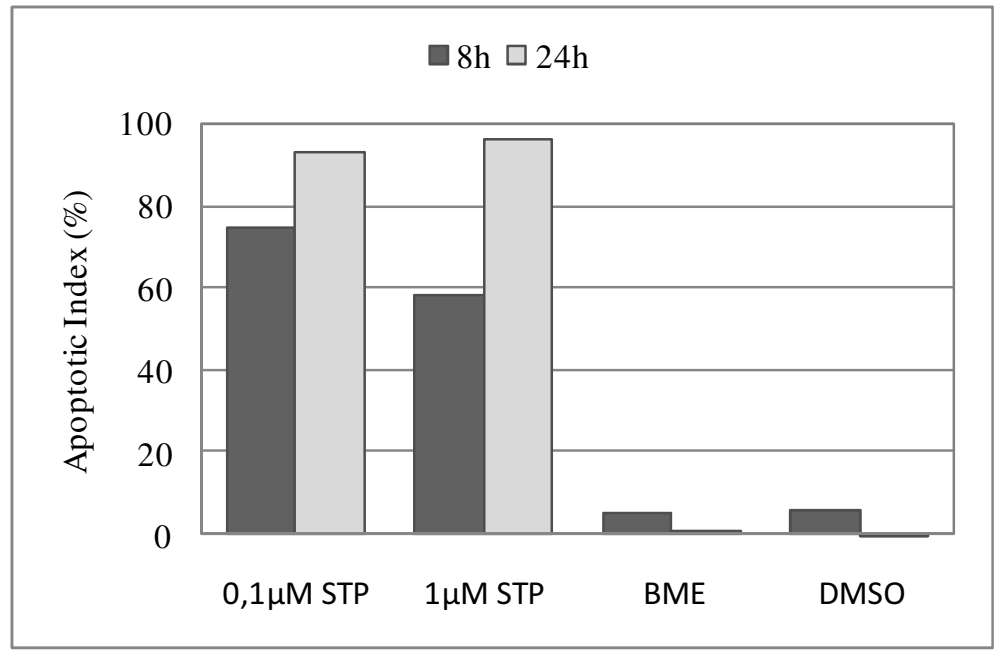

Fig. 2. Apoptotic Index (\%) was obtained by counting apoptotic nuclei after exposure for $8 \mathrm{~h}$ or $24 \mathrm{~h}$ to $0,1 \mu \mathrm{M}$ STP, $1 \mu \mathrm{M}$ STP, BME and DMSO 